\title{
Soil Processes and Properties That Distinguish Ecological Sites and States
}

\section{By Michael C. Duniway, Brandon T. Bestelmeyer, and Arlene Tugel}

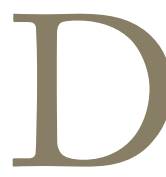
ifferences in ecological sites, and sometimes ecological states, are ultimately due to differences in soil properties and processes within a climatic zone. Soil properties are features of a soil, such as soil texture or soil depth. Soil processes are a series of actions in the soil that bring about a result, for example, water percolating into the soil that determines soil water amounts. Measured relationships between soil properties and soil processes allow us to estimate soil processes given information on a set of soil properties and other variables, such as rainfall amounts. For example, we can predict the rate at which water will percolate into a soil profile if we have data on soil properties such as texture, soil structure, bulk density, and organic matter.

How do we determine which soil properties and processes differ among ecological sites or ecological states? This is typically done by observing relationships between soils and the plant communities occurring on them. We inventory plant communities and soil properties within a climatic zone and look for statistical relationships among them. We then draw on research to infer the soil processes that occur and develop hypotheses about how those processes explain plant community patterns (see Moseley et al., this issue). Although soil and landform properties are used to describe the characteristics of ecological sites, it is the soil processes that are controlled by the properties that actually cause differences between ecological sites. Soil processes explain why ecological sites (and sometimes states) differ. ${ }^{1}$ The goal of this article is to equip developers and users of ecological site descriptions with a basic understanding of how differences in soils arise, the relationship between soil maps and ecological sites, and how soil properties affect soil processes to create differences among ecological sites and states. Our hope is that this understanding can be used to guide data collection and help develop narratives to explain the properties of ecological sites and states.

\section{Soil Development and Differentiation}

Soil development, or pedogenesis, describes how differences in soil properties arise. Properties of a soil are the result of the interaction of the five soil-forming factors: parent material, climate, topography, biota, and time. ${ }^{2}$ Parent material describes the geologic precursors of the soil (e.g., limestone bedrock, sandy alluvium, rock with high salt content). The principal climate variables considered in soil formation are temperature and precipitation, both of which affect the rates of soil processes. Topography refers to the context of the soil relative to the land surface shape and is described with such features as elevation, slope, landscape position, and aspect. Plants, animals, and microorganisms determine processes such as the accumulation of organic matter, development of soil aggregates, biochemical weathering, mixing of the soil profile, and cycling of water and nutrients. The soil-forming factor of time is the length of time over which soil development has occurred, which determines several subsoil properties. ${ }^{3}$

The properties of a particular soil are the result of soil-forming processes acting through time and under the influence of parent material, climate, topography, and biota. There are four general soil-forming processes: 1) transformations, which are the modification, loss, or creation of soil materials such as the breakdown of organic matter or the formation of secondary clays and carbonates; 2) translocations of soil material up or down the profile, mostly by water but also by soil organisms; 3) additions of new material to the soil, such as dust, organic matter, and soluble salts; and 4) losses from the soil profile due to such processes as leaching and erosion. The relative dominance of these four processes creates differences in soil properties at different depths. We group depths within a soil featuring similar properties into layers called soil horizons. ${ }^{3}$

Soil-forming processes have produced a wide variety of soils featuring differences in soil horizons occurring at 

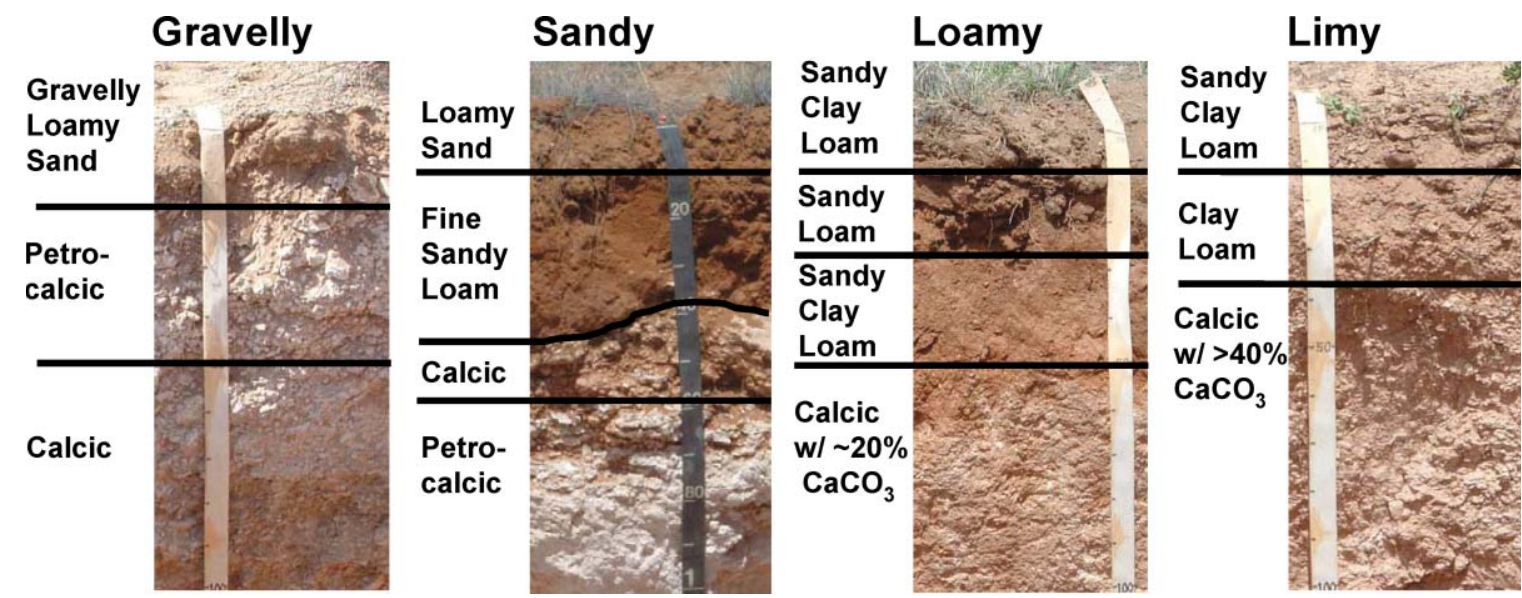

Figure 1. Soil profiles of four ecological sites (names in top row) in southern New Mexico (Major Land Resource Area 42.2) and horizon textures or names as described by soil taxonomy ${ }^{3}$ (to a depth of $1 \mathrm{~m}$, columns).

different depths (Fig. 1). To help us understand and manage soils, soil classification groups soils with similar arrangement of properties with depth (i.e., similar soil horizons). Ecological sites, in turn, classify (again) these soil classes according to their effects on vegetation and related processes.

\section{Soil Mapping, Classification and Relations to Ecological Sites and States}

Soil mapping divides the landscape into soil map units that include soils with different soil horizons or topographic positions. In the United States, the National Cooperative Soil Survey (NCSS) employs soil taxonomy ${ }^{4}$ and the soil series concept to classify the distinct soils within soil map units. ${ }^{4}$ Often it is impractical to delineate each individual soil that occurs in a landscape because the soils are difficult to distinguish using surface features (e.g., patterns in topography and vegetation) or the spatial extent of soil bodies is finer than the scale of mapping. Thus, soil map units often contain more than one soil. Distinct soils within map units are called soil map unit components and are identified as a soil series, soil taxonomic class, or miscellaneous area with little substrate that is identifiable soil (such as a rock outcrop). Soil map unit component names typically use the soil series name (e.g., Nickel; similar to a biological species name) plus the surface texture, slope, and in some cases other modifiers (e.g., "Nickel very gravelly fine sandy loam, 3-15\% slopes, eroded"). These modifiers identify the "soil phase" of a soil series. Soil map unit components repeat across the landscape and are the most finely resolved land units that are linked to ecological sites. The soil map units are then named using some of the contained map unit components (e.g., "Nickel-Upton association"; Fig. 2).

The NCSS uses four kinds of map units. 1) Consociations are dominated by one map unit component, and the others are "inclusions" that are relatively rare occurrences of dissimilar soils. Alternatively, map units can contain two or more common, dissimilar components that occur in predictable patterns but were not individually mapped. 2) Complexes are specified when the patterns are finer than the scale of mapping. 3) Associations are specified when the patterns are discernable at the mapping scale but the resources were not available to map them. 4) Undifferentiated groups combine different soils in map units because, at the time of mapping, it was determined that the use of the contained soils was severely limited due to features such as steepness, stoniness, or flooding. ${ }^{5}$ Because past soil mapping resources were primarily focused on crop agriculture, soil map units in rangelands are dominated by complexes, associations, and undifferentiated groups. Such map units often contain soils featuring different ecological potentials.

Ecological sites group soil map unit components, which support plant communities that have similar characteristics at potential and respond similarly to management and disturbance. ${ }^{6}$ The process of grouping soil components to ecological sites is called "soil-site correlation." Because a soil series is a relatively broad classification of soils, a soil series may be associated with more than one ecological site. The soil map unit component, however, can link the variants of a soil series to an ecological site. For example, in the Chihuahuan Desert area of southern New Mexico (Major Land Resource Area 42.2) the "Stellar clay loam, $0-3 \%$ slopes" is a Clayey site but the "Stellar clay loam, 0-3\% slopes, flooded" is a Bottomland site (Fig. 2). Therefore, soil map units that are consociations will be dominated by one ecological site whereas complexes, associations, and undistinguished groups will often contain more than one ecological site. The ecological sites contained within a single map unit are not necessarily similar. For example, in alluvial fan systems, very productive inset fan locations (e.g., Loamy; Fig. 1) are often grouped in the same map unit alongside less productive on-fan locations (e.g., Gravelly; Fig. 1) because they are predictably and finely intermingled. (For information on how to access NCSS soil maps and information on correlated ecological sites, see Talbot et al., this issue).

Each ecological site is associated with a state-andtransition model (STM) that describes the responses of 


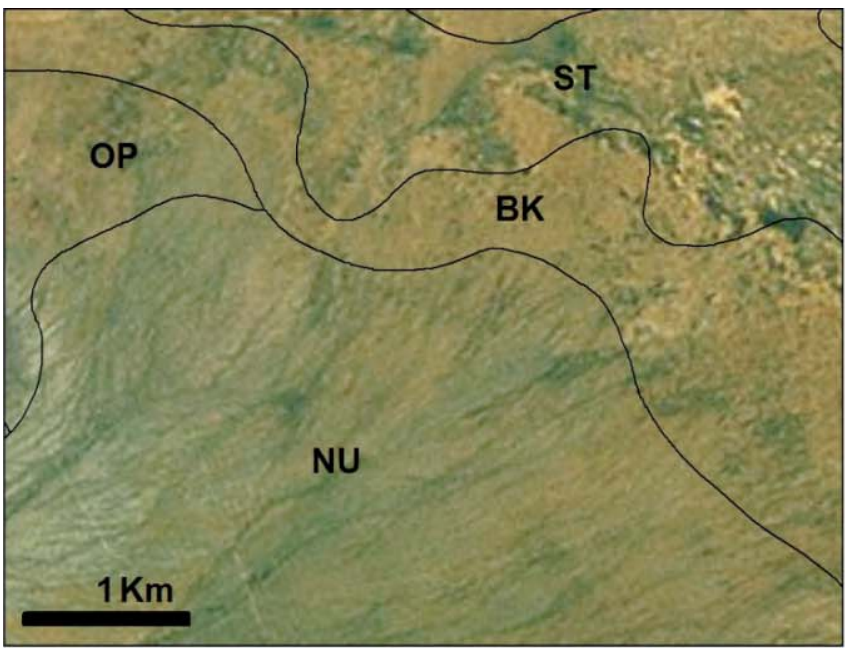

BK: Berino-Dona Ana association

$50 \%$ Berino fine sandy loam, 1-5 \% slopes = Sandy

$30 \%$ Dona Ana fine sandy loam, $1-5 \%$ slopes $=$ Sandy

$20 \%$ inclusions of Reagan, Stellar, Bucklebar,

Cacique, and Simona

\section{NU: Nickel-Upton association}

$50 \%$ Nickel very gravelly fine sandy loam, $3-15 \%$ slopes $=$ Gravelly

$25 \%$ Upton gravelly sandy loam, $3-5 \%$ slopes = Gravelly

$25 \%$ inclusions of Cave, Tencee, Simona, and similar soils

OP: Onite-Pajarito association

$40 \%$ Onite loamy sand, $1-4 \%$ slopes $=$ Sandy

$30 \%$ Pajarito fine sandy loam, 0-5\% slopes = Sandy

$15 \%$ Pintura fine sand, 0-5\% slopes= Deep sandy

$15 \%$ inclusions of Wink, Harrisburg, Simona, Berino, and Dona Ana

\section{ST: Stellar association}

$40 \%$ Stellar clay loam, $0-3 \%$ slopes $=$ Clayey

$40 \%$ Stellar clay loam, $0-3 \%$ slopes, flooded $=$

\section{Bottomland}

$20 \%$ inclusions of Reagan, Dona Ana, Berino, and

Mimbres

Figure 2. An example of a soil map with map units, percent composition of named map unit components and inclusions, and correlated ecological sites (in italics) for a small area in southern New Mexico (Doña Ana County, Major Land Resource Area 42.2).

vegetation to management and disturbance. The ecological states of STMs (Bestelmeyer et al., this issue) tend to exhibit large differences in plant composition and ecosystem processes. In many (but not all) cases, soil properties and processes, particularly of the soil surface, differ among ecological states and control their dynamics. For example, shrub encroachment and loss of grasses is often associated with increased erosion and loss of organic matter-rich surface horizons. These differences are sometimes reflected in soil mapping via phases (e.g., an eroded phase) but more often differences in states are not reflected in soil classification or mapping because the associated properties vary over time in response to management and disturbance.

\section{Soil Properties That Distinguish Ecological Sites}

In this section we identify how specific soil properties and processes can be used to distinguish ecological sites within an individual geographic region with similar climate (e.g., a Major Land Resource Area or Land Resource Unit). The soil properties that distinguish ecological sites are those that control the inherent potential of the site to support distinct plant communities. In distinguishing ecological sites, we should avoid soil properties that are sensitive to common management and disturbance scenarios (e.g., grazing, fire), which are addressed in STMs. The primary properties considered in differentiating ecological sites within a climatic zone are topographic features (landscape position and aspect), soil texture, soil mineralogy, and soil depth. Rather than organize our discussion around each of these soil properties, we instead organize the discussion according to soil resources and processes determining the access of plants to these resources (Fig. 3). These are the primary ecological mechanisms leading to differences among ecological sites. Tools for soil classification related to ecological sites are available at the USDA Natural Resources Conservation Service (NRCS) soil classification Web page (http://soils.usda.gov/technical/classification).

\section{Soil Water Availability}

Soil water availability is perhaps the most common factor distinguishing rangeland ecological sites. Several soil properties affect soil water availability. First is surface shape, including landscape position (run-in vs. runoff), slope (shallow or steep), and aspect (south- vs. north-facing), which determines plant microclimate and water movement. For example, in the northern hemisphere, south-facing aspects produce warmer conditions at the soil surface and increased rates of transpiration and evaporation compared with north-facing aspects (Figs. 3A and 3B). Downslope or bottom landscape positions will often receive run-in water from upslope areas and have greater effective precipitation than non-run-in locations (Fig. 3C).

Second is soil texture and coarse fragment content of surface soils, which affect infiltration and evaporation. For example, during a rainstorm, sandy surface textures typically allow more rapid infiltration than clayey textures. When dry, however, clayey soils tend to lose more water to evaporation than sandy-textured soils. Surface coarse fragments can reduce infiltration capacity but can also limit water loss due to evaporation. For example, a gravelly loam has a slower maximum infiltration rate than a nongravelly loam, but the gravelly loam would typically experience a lower rate of evaporative water loss. The texture of fine soil $(<2 \mathrm{~mm})$ and coarse fragment content $(>2 \mathrm{~mm}$ ) often vary independently 

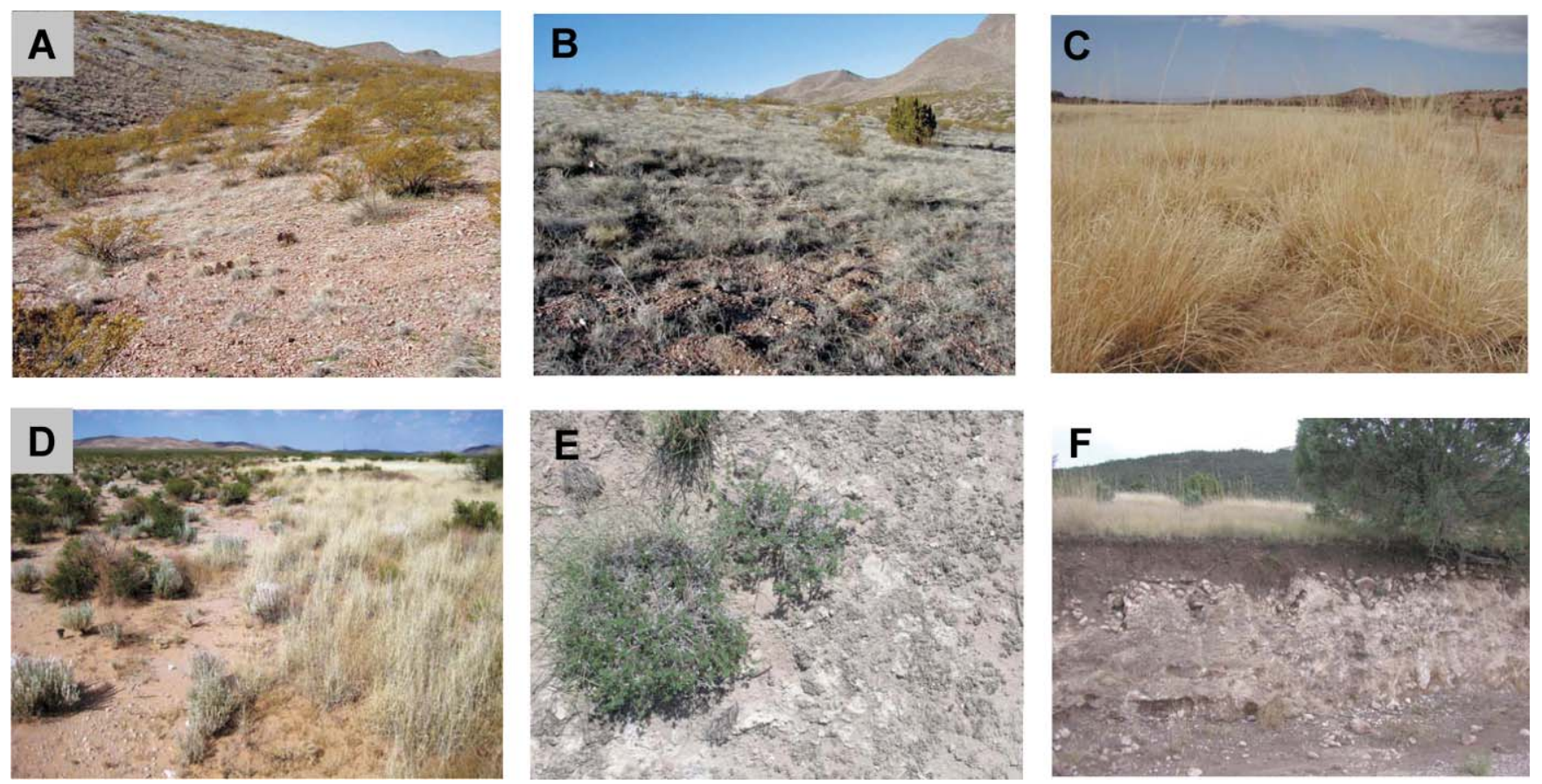

Figure 3. Static soil properties used to distinguish ecological sites. A, A sparsely vegetated south-facing vs. B, a highly vegetated north-facing aspect in the same area; $\mathbf{C}$, a bottomland ecological site with high production supported by run-in water; $\mathbf{D}$, the effects of an abrupt increase in subsoil clay (from left to right); $\mathbf{E}$, a gypsum-affected site; and $\mathbf{F}$, a soil shallow to a petrocalcic horizon.

of one another, so that clayey to sandy soils can be associated with varying gravel content (e.g., a clayey vs. gravelly clay ecological site).

Third are subsurface soil properties that influence the depth to which infiltrated water penetrates into the soil profile and the residence time of water available to plants (Fig. 3D). Subsoil structure, such as the prismatic structure of many clay soils, can increase the depth of wetting due to formation of macropores. Such soils can be very productive. Finer-textured subsoil horizons (e.g., loamy) can retain more infiltrated water than coarse-textured subsoils (e.g., sandy), thus providing more water for plants for longer periods after the rains have stopped. Texture contrasts can also be important. For example, a dry loamy sand horizon over a wet clay loam horizon will function similarly to a mulch and reduce evaporative losses. Ecological site distinctions should consider the combination of surface and subsurface textures.

\section{Soil Nutrient Availability}

Differences in soil texture and mineralogy can cause important differences in plant nutrient availability. For example, sites with high amounts of gypsum in the soil profile tend to have limitations in mineral nutrients such as nitrogen, phosphorus, and potassium (Fig. 3E). Most of the ecological sites that have been developed thus far occur on Western rangelands-ecosystems that are often limited by water availability more than nutrients. Soil properties used to differentiate rangeland ecological sites are not often specifically related to nutrient availability. Where the ecological site concept is applied to more mesic areas, soil nutrient availability can be used to differentiate ecological sites. For example, soil age is an important distinguishing feature of some ecological sites in Hawaii because, in part, plantavailable phosphorus tends to decrease and plant-available nitrogen tends to increase with soil age. ${ }^{7}$

\section{Plant Rooting}

The depth to a root-limiting layer can determine the ability of different plant species to access water and other resources. Restrictive horizons include petrocalcic (caliche) and petrogypsic horizons, duripans, fragipans, and bedrock. ${ }^{3}$ All of these will stop or slow the elongation of roots and reduce the available rooting volume in the soil (i.e., "shallow" sites; Fig. 3F). These properties, however, do not always correspond to reduced plant-available water. Several studies have illustrated the availability and utilization of water within rocks and rock-like soil. ${ }^{8}$ The continuity of such horizons is also important. Cracks and fissures can both trap water and facilitate access to water contained within the matrix of the restrictive horizon. ${ }^{8}$ For example, ecological sites with soils shallow to limestone can be very productive, even when much of the area is exposed rock. Another root-limiting property for many species is depth to the water table (e.g., meadow sites).

\section{Soil Stability and Redistribution}

Differences in the propensity of soils to erode can determine disturbances to plants that interrupt their ability to access resources, for example, by exposing roots or burying plants. 

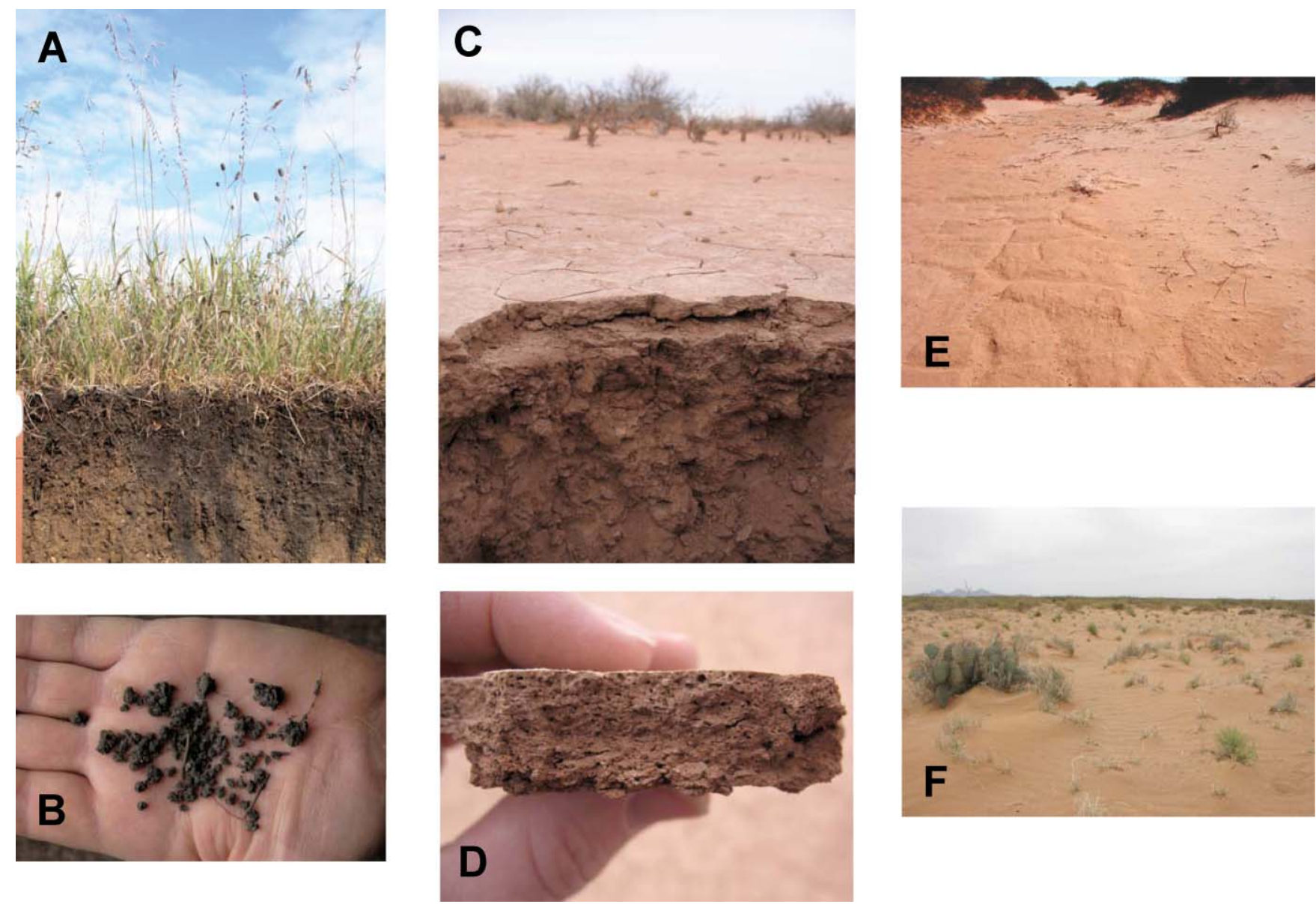

Figure 4. Dynamic soil properties used to distinguish states. A, A surface horizon darkened by organic matter and $\mathbf{B}$, stable soil aggregates from that soil horizon (photos courtesy of Bruce Kunze); C, D, a strong physical crust in a silty soil; E, a soil that has been eroded to expose a very hard clay- and carbonate-rich subsoil; and $\mathbf{F}$, deposition of eroded soil that is burying grasses.

Erodibility is the susceptibility of a soil to erosive forces (wind and rain). Surface soils that form stable aggregates (clumps of soil particles glued together by organic matter or clay) are less erodible than nonaggregated soils. For example, the fine texture and typically higher organic matter of surface horizons in a loamy compared to a sandy ecological site enhances the formation of stable aggregates and reduces erodibility. Erosivity is the ability of an erosion agent (e.g., water) to cause erosion and is influenced by many interacting properties and processes. For example, finertextured soils on sloping sites (e.g., "loamy slopes," ecological sites with $>5 \%$ slopes) can produce runoff with a greater erosive force than coarser-textured or more level sites.

\section{Soil Properties That Distinguish Ecological States}

Plant community characteristics are typically used to distinguish ecological states within an ecological site, but surface soil properties can also be important for distinguishing ecological states. Unlike those used to distinguish ecological sites, properties used to distinguish ecological states are relatively dynamic with respect to disturbance, management, and recent climate. ${ }^{6}$ Dynamic soil properties are consequences of interactions between surface soil, plant communities, and land use. ${ }^{9}$ Dynamic soil properties that are commonly used to distinguish ecological states include soil organic matter, soil structure, and related processes such as soil stability and redistribution (erosion and deposition; Fig. 4). Soil properties that contribute to differences among ecological states are typically near the soil surface and therefore easily changed when vegetation is altered or physical disturbances (such as vehicle traffic) are directly applied (Fig. 5). The organization below is the same as for the discussion of ecological sites above because dynamic soil properties similarly affect soil resources and plant access to them. For some specific measurements and indicators of dynamic soil properties, interested users can see the USDA NRCS Soil Change Guide (http://soils.usda.gov/technical/ soil_change/).

\section{Soil Water Availability}

Dynamic soil properties that affect water availability are primarily associated with surface soil infiltration rate and water retention. For example, the plant-soil feedbacks in a 

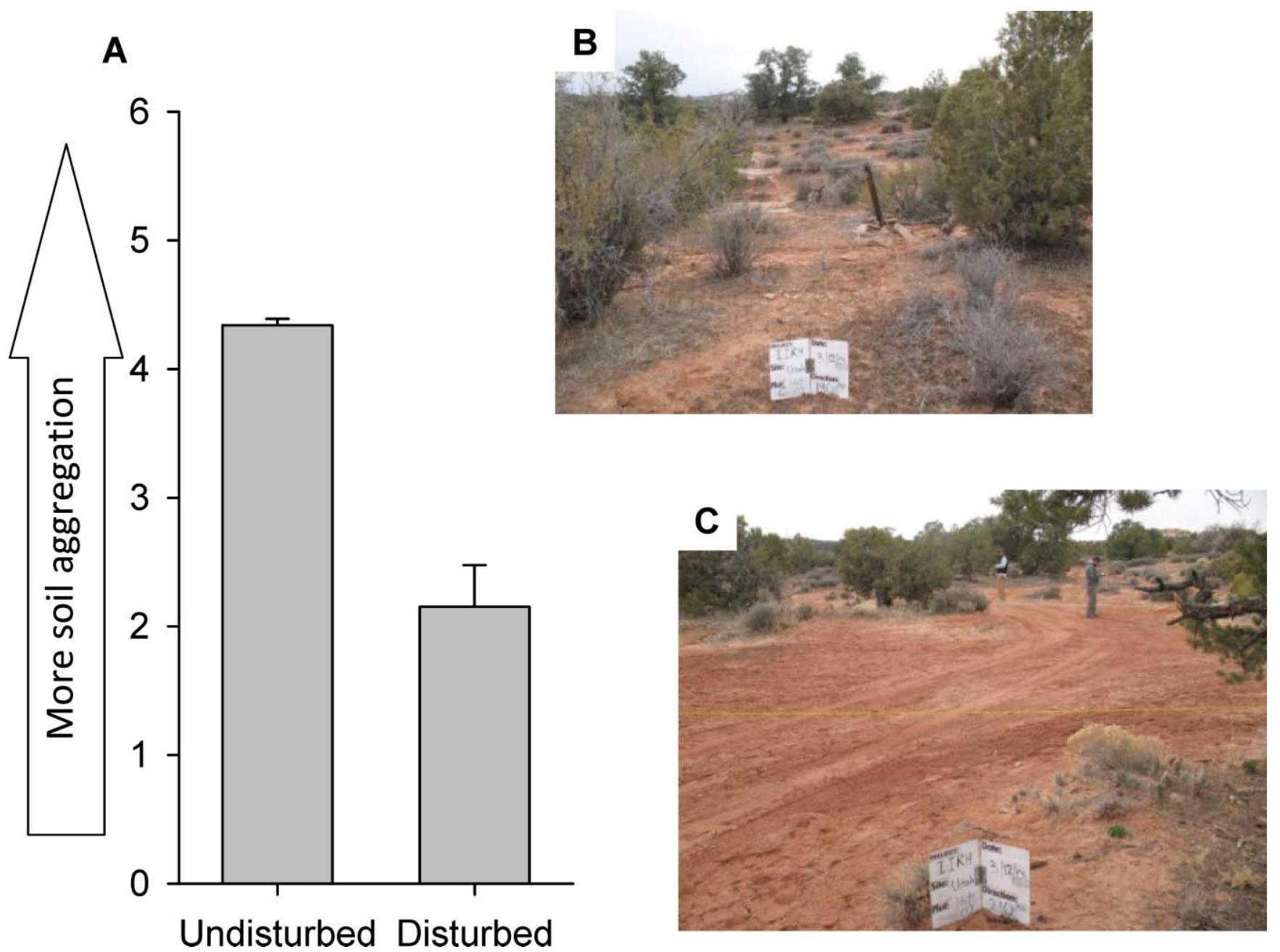

Figure 5. Example of a dynamic, use-dependent soil property differing between ecological states. A, Soil aggregation in this shallow sandy loam ecological site in southern Utah (site no. 035XY236UT) is much greater in B, the undisturbed sites than in C, sites disturbed by off-highway vehicle use. $^{11}$

grassland state often increase surface soil infiltration rates and water retention by increasing soil organic matter content that promotes soil aggregate formation (Figs. 4A and $4 \mathrm{~B})$. Surface disturbance of soils can break up soil aggregates and compact soils, thus reducing infiltration rates and increasing evaporative losses (Fig. 5). In soils with high silt content, thick physical crusts can form that reduce infiltration in states with low cover (e.g., a shrub-dominated state; Figs. 4C and 4D). Through interactions with erosion processes, near-surface soil texture can be altered due to the loss of surface soil and exposure of subsurface horizons with differing texture (Fig. 4E). Alternatively, surface texture can change through deposition of new material of a different texture (Fig. 4F). Changes in vegetation cover can also affect the soil water. For example, a sod-bound state features increased runoff and reduced infiltration rates due to a change in grass life-forms.

\section{Soil Nutrient Availability}

Changes to plant production and plant composition will alter the type and amount of organic matter inputs, which affect rates of decomposition and nutrient inputs. For example, a grassland state will have higher inputs of readily decomposable organic matter (in the form of fine roots) than a shrubland state. Through interactions with erosional processes, decomposition rates can change and nutrients can be redistributed or lost. For example, loss of protective grass cover in the shrubland state of a sandy ecological site can lead to increased erosion and concentration of nutrients under shrub canopies.

\section{Plant Rooting}

Plant anchorage and root elongation can be affected by dynamic soil properties. Severe soil compaction can interfere with root elongation (e.g., compaction layers just below the surface in sandy loam soils that have lost grass cover). Surface crusting can complicate seedling establishment by either limiting seed burial or restricting emergence (e.g., Figs. 4C and 4D). Severe erosion in soils shallow to restrictive layers can greatly reduce the available rooting volume. For example, loss of the surface soil horizon in 
shrub interspaces can expose subsurface clay- or calcium carbonate-rich horizons. The resulting hardpan at the soil surface can greatly restrict plant establishment (Fig. 4E).

\section{Soil Stability and Redistribution}

Soil organic matter and biota affect soil aggregation that limits erosion due to raindrop impact, sheet flow, and wind. The amount and distribution of bare, unprotected soil affects the erosivity of wind and overland water flow. For example, a gullied state could be the result of the interaction of reduced infiltration due to compaction, increased erodibility due to loss of water-stable soil aggregates, and increased erosivity of overland flow due to large and interconnected bare patches.

\section{Conclusions}

Research on properties of the soil profile underpinning ecological sites has been ongoing for decades and is generally well understood. The relationship of soil properties to the development of alternative states, however, is only beginning to be understood. Plant community composition and cover have been the primary distinguishing properties of ecological states. In published STMs, there is much less guidance on how soil properties and processes can be used to distinguish ecological states. There are cases in which soil properties may be unaffected by state change, but there are often cases in which soil properties play important roles that are not recognized. For example, plant-to-plant competition is often invoked as the mechanism maintaining alternate states when plant-soil feedbacks or soil-surface effects on plant resources are more important mechanisms. These different explanations have significant implications for the management practices discussed in STMs.

Additionally, it is possible that some soil properties could be used as indicators of impending state changes. ${ }^{6}$ For example, loss of infiltration capacity, as indicated by degraded surface soil structure and associated changes to water cycling, could be a key process leading to a change from a grassto shrub-dominated state. Ecological site science would benefit from the development of systematic protocols for recognizing differences in soil properties and processes among ecological states. ${ }^{10}$

Like any system for grouping parts of the landscape, ecological sites and states are concepts made by humans and the boundaries can appear arbitrary. It is important to recognize that a continuum of properties and resultant processes exist with these boundaries. This variability can create variations in ecological potential and response to disturbance within a state or ecological site (Moseley et al., this issue). The increased availability of high-resolution terrain and spectral data and new soil mapping techniques may one day allow ecological site developers to view the distribution of soil properties across the landscape in finer spatial detail. Overlain maps of soil properties and plant community characteristics could potentially be used to understand plant-soil relationships spanning ecological sites and states simultaneously. The ecological site and ecological state concepts, however, will continue to provide a useful mechanism for organizing landscapes into units that explain variations in ecological processes.

\section{References}

1. Monger, H. C., And B. T. Bestelmeyer. 2006. The soilgeomorphic template and biotic change in deserts. Journal of Arid Environments 65:207-218.

2. Jenny, H. 1941. Factors of soil formation. A system of quantitative pedology. New York, NY, USA: McGraw-Hill. 281 p.

3. Birkland, P. W. 1999. Soils and geomorphology. New York, NY, USA: Oxford University Press. 430 p.

4. Soil Survey Staff. 1999. Soil taxonomy: a basic system of soil classification for making and interpreting soil surveys. Washington, DC, USA: US Government Printing Office. 869 p.

5. USDA Natural Resources Conservation Service. 2009. National soil survey handbook, title 430-VI. Available at: http://soils.usda.gov/technical/handbook/. Accessed 30 August 2010.

6. USDA Natural Resources Conservation Service. 1997. Ecological sites and forage suitability groups. In: National range and pasture handbook. Washington, DC, USA: USDA. p. 3-1-3-120.

7. Vitousek, P. M., S. Porder, B. Z. Houlton, and O. A. Chadwick. 2010. Terrestrial phosphorus limitation: mechanisms, implications, and nitrogen-phosphorus interactions. Ecological Applications 20:5-15.

8. Schwinning, S. 2010. Ecohydrology bearings-invited commentary-the ecohydrology of roots in rocks. Ecohydrology 3:238-245.

9. Tugel, A. J., J. E. Herrick, J. R. Brown, M. J. Mausbach, W. Puckett, and K. Hipple. 2005. Soil change, soil survey, and natural resources decision making: a blueprint for action. Soil Science Society of America Journal 69:738-747.

10. Tugel, A. J., S. A. Wills, And J. E. Herrick. 2008. Soil change guide: procedures for soil survey and resource inventory, version 1.1. Lincoln, NE, USA: USDA Natural Resources Conservation Service, National Soil Survey Center. Available at: http://soils.usda.gov/technical/soil\%5Fchange/. Accessed 16 November 2010.

11. Duniway, M., J. Herrick, D. Pyke, and D. Toledo. 2010. Assessing transportation infrastructure impacts on rangelands: test of a standard rangeland assessment protocol. Rangeland Ecology E' Management 63:524-536.

Authors are Research Soil Scientist, mduniway@nmsu.edu (Duniway) and Research Ecologist (Bestelmeyer), USDAAgricultural Research Service Jornada Experimental Range, Las Cruces, NM 88003, USA; and Soil Scientist (retired), USDANatural Resources Conservation Service Jornada Experimental Range, Las Cruces, NM 88003, USA (Tugel). 